\title{
BREVE ANÁLISE DE EVENTOS DE VIOLÊNCIA NA HISTÓRIA DE EL SALVADOR EM PERSPECTIVA COM SUA ATUALIDADE
}

\author{
Rafael Trevizol Viam Gaddini ${ }^{1}$ \\ Adriane Aparecida Moreira de Souza ${ }^{2}$ \\ Valéria Regina Zanetti ${ }^{3}$
}

\begin{abstract}
Resumo: Este artigo analisa aspectos importantes da história da violência em El Salvador visando compreender o panorama da atualidade do país, em que grupos de crime organizado, ou gangues, disputam territórios e poder entre si e com o Estado. Faz-se aqui uma análise sobre a história de dominação colonial e acontecimentos-chave ocorridos em El Salvador no século XX, sendo eles a matança de 1932 e a guerra civil (1980-1992). O artigo se apoia na hipótese de que os eventos atuais de violência não são subprodutos de um presente recente ou especificamente produzidos pelo movimento das gangues, mas uma reprodução histórica e contínua de injustiça social para com sua população, por uma acentuada impunidade e exploração por militares, elite fundiária e forças externas - no caso, a metrópole burguesa europeia.
\end{abstract}

Palavras-chave: El Salvador; Violência; História; Impunidade; Homicídio.

\footnotetext{
${ }^{1}$ Curso de História/UNIVAP, Brasil. E-mail: rafaeltvg@gmail.com.

2 Faculdade de Educação e Artes/UNIVAP, Brasil. E-mail: adriane@univap.br.

${ }^{3}$ Curso de História/UNIVAP, Brasil. E-mail: vzanetti@univap.br.
} 